Carlos Hallet, s.j.

Profesor de la Universidad Católica del Norte

Antofagasta-Chile

\title{
La discretio en Beniamin minor de Ricardo de San Víctor
}

En su obra Benjamín menor o Sobre los Patriarcas o De los Doce Patriarcas, Ricardo de San Víctor, además de ofrecernos un comentario sobre un episodio importante del Libro del Génesis, nos regala todo un tratado de espiritualidad, el cual quiere ser una preparación del espíritu a la contemplación. Parte de una interpretación del nombre y de la historia de cada uno de los doce hijos que Jacob tuvo de sus dos esposas, Lía y Raquel, y de sus sirvientas, Zelfa o Zelpá y Bala o Bilhá (Génesis 35, 22-26) (1).

\section{A. ELEMENTOS ANTROPOLÓGICOS}

En su concepción del hombre, creado a imagen y semejanza de Dios (Génesis $1,27)$, pero actualmente viciado por la ignorancia y la concupiscencia a causa del pecado, Ricardo distingue formalmente la parte imagen, que se caracteriza por la razón y el intelecto, y la semejanza, que es affectio o deseos y amor.

La ratio, simbolizada por Raquel, y la affectio, representada por Lía, son las esposas del espíritu racional. Ambas son herederas del Reino de los Cielos (B.m. III). La affectio recibe un soplo divino que la enciende y la ratio es iluminada por una revelación. La primera adhiere a las normas de la justicia, la segunda se eleva hasta la contemplación de la sabiduría eterna (B.m. IV).

La antropología de Ricardo no es simple. Cuando se expresa respecto del conocimiento operado por la ratio, distingue los conocimientos relacionados con los

(1) El texto que seguimos y al que nos referimos es el establecido por Jean Châtillon y Monique Duchet-Suchaux: Richard de Saint-Victor, Les douze Patriarches ou Beniamin minor, publicado en Sources Chrétiennes, $N^{\circ}$ 419, Cerf, Paris, 1997. En las referencias usaremos la abreviación "B.m".

La Patrología Latina de Migne lo ha publicado bajo el siguiente título: De praeparatione animi ad contemplationem. Liber dictus Beniamin minor, t. 196, 2a ed., 1880.

Sobre el autor y su obra, ver J. Châtillon, Richard de Saint-Victor, Dictionnaire de Spiritualité 13, 1988 , cc. 652-654.

Sobre la discretio, ver André Cabassut, Discretio, Dictionnaire de Spiritualité 3, 1954, cc. 13111330. 
sentidos, la imaginación, la razón ut sic y el intelecto o inteligencia. Los sentidos permiten conocer las realidades corporales y exteriores. La imaginación, simbolizada por Bala, la sierva de Raquel, puede actuar sin control y divagar, pero también, como buena empleada de la ratio, puede llevar el nombre de su ama y en calidad de imaginatio rationalis forma imágenes nuevas a partir de lo que enseñan los sentidos. Esta imaginatio rationalis es capaz de mirar hacia delante: ella considera tanto los males del futuro, las penas eternas, como los bienes de la eternidad. En la primera de estas funciones, ella da a luz a Dan, cuyo papel consiste en reprimir los vicios gracias a la representación de los castigos. La segunda función produce a Neftalí, que, al hacer ver las recompensas del cielo, suscita los buenos deseos.

La ratio es Raquel, quien alcanza las realidades inteligibles, por ejemplo, el alma. Su función principal es la discretio. La discretio es José, el primer hijo de Raquel y el undécimo de Jacob. Es hijo tardío, porque la perfecta discretio no se consigue sino por una larga práctica y una gran experiencia (B.m. LXVII). La discretio, que es la facultad de distinguir y de moderar, está también relacionada con el conocimiento de sí mismo (B.m. LXX).

Por su parte, la inteligencia o intelecto tiene como función llegar a lo meramente "intelectibile", a lo que no puede ser imaginado, como la naturaleza divina o el misterio de la Santísima Trinidad (Beniamin maior I, 7; V, 9).

Al lado de Raquel y Bala, otras fuerzas actúan en el hombre: Lía y Zelfa, la affectio y la sensualitas (2). Esta última es buena, porque aporta el sabor a las cosas, pero debe ser controlada, aún más que la imaginación.

Lía tuvo a seis hijos: Rubén, que simboliza el temor; Simeón, imagen del dolor; Leví, que representa la promesa del perdón; Judá, que es el amor del bien y de la justicia; Isacar, la alegría interior del alma purificada, y Zabulón, el odio a los vicios. También tuvo a una hija, Dina, símbolo del pudor. Los hijos adoptivos de Lía, nacidos de su sierva Zelpa, son otros símbolos de virtudes: Gad es la abstinencia y Aser la paciencia. Todos esos hijos son affectus, que pasan a ser virtudes, cuando son ordenados y medidos. Ahora bien, ese orden, esa moderación son frutos de la discretio ejercida por la ratio. Sin la discretio, esos affectus, en vez de ser virtudes, serían vicios.

Como se puede constatar, la discretio es fundamental para dominar tanto la imaginación como los affectus. Ella está en el centro de la espiritualidad ricardiana y sin ella el acceso a la contemplación, representada por Benjamín, segundo hijo de Raquel y duodécimo de Jacob, sería totalmente imposible.

\section{B. LA DISCRETIO SEGÚN EL BENIAMIN MINOR}

Como José es hijo de Raquel así la discretio es función de la ratio. Ella es fundamentalmente la facultad de discernir, pero ella es también la capacidad de moderar. En el texto de Ricardo, la palabra discretio tiene los dos significados, "discernimiento" y "moderación". Cada sentido es reconocible según los contextos, según se trata de la ratio o de la affectio.

J. Châtillon traduce "sensualitas" por "sensibilité". 


\section{Ratio $y$ affectio}

A la affectio, Ricardo le atribuye como rol preponderante el amor, a la ratio le corresponde la discretio o el discernir. A todo espíritu razonable, el Padre de las luces le ha dado una doble fuerza: la ratio qua discernamos y la affectio qua diligamos, y ambas son acompañadas por la discretio. La primera, discerniendo, puede llegar a la verdad; la segunda, por la discreción o moderación, puede alcanzar la virtud. Es con la discretio como de la ratio nacen, al lado de los sentidos espirituales, los juicios rectos y la verdad; de la affectio surgen los santos deseos, los afectos ordenados y toda virtud (B.m. III).

La ratio o Raquel, además de discernir, es capaz de meditar, contemplar y comprender, mientras Lía o la affectio llora, se aflige, gime y suspira al recordar sus pecados (B.m. IV). Lía tiene la sensualitas a su servicio, la ratio es ama de la imaginación. Estas dos siervas deben ser sometidas a las normas de la discretio y ser ordenadas. Temor, dolor, esperanza, amor, abstinencia, paciencia, alegría, pudor y sufrimiento deben ser moderados al igual que los deseos de los sentidos. Esa moderación es tarea y resultado de la discretio entendida como discernimiento cuando está relacionada con la ratio y como moderación cuando se refiere a la affectio.

\section{Importancia y necesidad de la discretio}

El caso de Rubén, culpable de incesto (Génesis 49, 3-4), nos enseña que el temor, por muy santo que sea en sí, conduce hacia grandes peligros, si no está moderado por la discretio (B.m. LXV). Pasa lo mismo con todos los demás affectus. Deben ser mantenidos dentro de los límites de la aequitas. El dolor excesivo así como la esperanza desmedida son malos. Cada cual debe controlar con mucho cuidado todos sus afectos para que estén no solamente ordenados, sino también moderados. En efecto, aquel que vive en una situación de temor ilimitado puede caer en la desesperanza; un dolor demasiado grande se transforma en amargura; aquel que se fía de una esperanza desmedida es presuntuoso; el amor exagerado cae en la adulación; una alegría desbordante conduce a la disipación; la ira descontrolada se transforma en furor. Sin la discretio, las virtudes pasan a ser vicios (B.m. LXVI).

\section{Origen de la discretio}

Símbolo de la discretio, José nace de Raquel. No podía nacer de otra mujer, ni de ninguna sirvienta, ni tampoco de Lía, porque la discretio en sí no es atributo de la sensibilidad, de la imaginación o de la affectio, sino que es función de la razón, como lo es también la inteligencia.

José nació tarde, pero fue el más amado de los hijos de Jacob (Génesis 37, 6). Que haya sido el preferido no es de extrañar, ya que sin la discretio ninguna otra virtud puede ser conseguida ni mantenida. Que haya nacido tarde, tampoco es raro, ya que no se llega a la discretio sino después de mucha práctica y una larga experiencia. Primero es necesario que ejerzamos las virtudes una por una y constatemos, en el caso de cada cual, si somos capaces de practicarla antes de conocerla bien y 
poder discernir lo que le atañe. Podemos aprender mucho sobre la discretio por la lectura, las enseñanzas de algunos maestros o por algo innato que esté en nuestra razón, pero su pleno conocimiento solo lo conseguimos por la experiencia. Es lógico, entonces, que esta virtud, que debe juzgar a las demás, aparezca después de todas ellas.

A pesar de consagrar todos nuestros esfuerzos a la práctica de cada virtud, es inevitable que caigamos a menudo. Es levantándonos repetidas veces como podremos aprender con qué vigilancia y precauciones se llega a poseer y conservar el tesoro de las virtudes y es así como conseguiremos finalmente una perfecta discretio de nuestros comportamientos, la virtud de consejo y la prudencia, que vale más que el vigor físico, según la Vulgata (Sabiduría 6, 1; Proverbios 16, 12).

\section{Características de la discretio}

Según Ricardo, la discretio es la única que, por medio de su prudencia, permite que una acción alcance su plena realización y llegue a su último término.

La verdadera discretio es la virtud que custodia a las demás; es capaz de entrever, a través de los fantasmas y de las tentaciones, los peligros y las trampas. Ella también protege la pureza interior y señala al espíritu todo lo que pueden sufrir las virtudes.

Si se multiplican las tentaciones y los peligros, la discretio, en vez de disminuir, crece y su aprendizaje se perfecciona. Los daños sufridos por las demás virtudes le ayudan a crecer (B.m. LXVIII).

Virtud excelente y soberana, la discretio es la que indica el camino a seguir a la inteligencia y al ojo interior del corazón, es la que afina la intención del espíritu, que corrige las negligencias y los excesos de las demás virtudes, igual como ante José sus hermanos no pueden hacer nada que sea inoportuno. Ella puede parecer demasiado severa, dura, hasta insoportable, porque lo más difícil es hacer todo lo que corresponde, no descuidar nada, no perturbar el orden, no sobrepasar nunca la medida y obligarse a medir sus afectos. Puede darse incluso que el espíritu se entusiasme y emprenda cosas inútiles o imposibles, con una audacia presuntuosa y sin límites, hasta pervertir las intenciones del corazón y caer en el pecado de hipocresía, crimen gravísimo, el más abominable de todos (B.m. LXIX).

\section{Deberes de la discretio}

Frente a la hipocresía, la discretio tiene muchas tareas: mirarla con circunspección y en forma precavida, prevenirse contra ella con cuidado, sorprenderla en forma habilosa y denunciarla con mucha severidad.

Debe actuar de la misma manera ante cualquier otro mal que se acerque insidiosamente. A José le toca cuidar a todos sus hermanos y velar por ellos. Así, la discretio debe normar la conducta de cada virtud, gobernar sus actos y ocuparse de su futuro. Es su obligación observar con mucha atención y examinar frecuentemente en cuánto el espíritu progresa cada día y en cuánto retrocede, qué pensamientos lo asedian y qué sentimientos lo rozan con más frecuencia. 
Debe conocer perfectamente, además de los defectos del corazón, los achaques del cuerpo y buscar y aplicar los remedios que se necesitan en cada caso.

Pero la discretio no debe solo ubicar los vicios: le corresponde también enterarse de los dones de la gracia y de los méritos de la virtud. Debe, además, distinguir y apreciar con exactitud cuáles son los bienes de la naturaleza y cuáles son los dones de la gracia. Debe conocer todo: las maquinaciones y tentaciones del espíritu maligno, la abundancia de las alegrías y de las consolaciones espirituales, la frecuencia de las visitas del Espíritu divino, el modo multiforme con que ese Espíritu, a pesar de ser único, lo llena unas veces del espíritu de sabiduría, otras veces del espíritu de inteligencia, otras del espíritu de coraje o de cualquier otro efecto de su acción.

En resumen, debe conocer perfectamente, en la medida de lo posible, el estado y las disposiciones del hombre interior y exterior en su totalidad y debe preguntarse esmeradamente no solamente cómo es, sino cómo debe ser (B.m. LXX).

\section{Conocimiento de sí mismo y conocimiento de Dios}

Es gracias a José, la discretio, como el espíritu no cesa de instruirse hasta llegar, a veces, hasta el pleno conocimiento de sí mismo, mientras que gracias a Benjamín, su hermano uterino, le toca, otras veces, ser levantado hasta la contemplación de Dios. Si José representa la gracia de la discretio, Benjamín es la gracia de la contemplación. Ambos nacen de la misma madre, Raquel, pues es por la razón como se llega al conocimiento de Dios y de sí mismo.

Benjamín nace mucho tiempo después de José, porque el espíritu necesita ejercitarse largamente en el conocimiento de sí mismo y ser plenamente instruido en él antes de poder ser levantado hasta el conocimiento de Dios. Es imposible conocer los misterios invisibles de Dios, si no se es capaz de conocer lo invisible que está en uno. El hombre no puede tampoco pretender conocer lo que está encima de él, si no es capaz de conocerse a sí mismo.

Ahora bien, es en sí mismo donde el espíritu razonable encuentra su primer espejo para ver a Dios. Nos dice san Pablo que "vemos en un espejo" ( $1^{a}$ Corintios $13,12)$. El principal espejo y el más apto para que el hombre pueda ver la imagen de Dios es su propio espíritu, ya que, según creemos, el hombre ha sido hecho a imagen y semejanza de su Creador (Génesis 1,26). Pero para ver a Dios hay que limpiar el espejo, hay que purificar el espíritu. A José, la discretio, le toca sujetar ese espejo para que no caiga y, si ha caído, le corresponde actuar para que no quede pegado al suelo por el amor de las realidades terrenales; debe limpiarlo para que el polvo de los pensamientos vanos no lo ensucie y mirarlo para que el ojo de la intención no se desvíe hacia indagaciones inútiles. Hasta aquí el papel de José y de la discretio: ayudar al espíritu hasta que Benjamín, la contemplación, sea concebido y que la razón, Raquel, desfallezca para dar a luz a Benjamín, que es la contemplación de Dios a la cual nadie puede llegar por sus propias fuerzas, sino por el excessus mentis o el rapto, que arrebató a san Pablo hasta el tercer cielo $\left(2^{a}\right.$ Corintios 12,2$)$ (B.m. LXXI-LXXIV). 


\section{LA DISCRETIO, RICARDO DE SAN VÍCTOR Y LA TRADICIÓN}

\section{De la discretio a la prudencia}

La palabra discretio aparece dentro de una tradición ascética cristiana donde tuvo como ancestros los vocablos griegos "diácrisis", "discernimiento" y "métron", “medida”. Además de significar, en un primer tiempo, "separación”, “distinción”, adquirió poco a poco el significado de "capacidad o facultad de discernir" y luego correspondió a la razón y a sus actos, principalmente el juicio y la prudencia.

La "diácrisis" paulina de $1^{a}$ Corintios 12,10 se tradujo por "discernimiento de los espíritus" y en Hebreos 5, 14, por "discernimiento entre el bien y el mal".

A partir de Juan Casiano, discretio involucró la idea de "medida", al designar la virtud que mantiene el celo dentro de un término medio.

Discernimiento, justo medio, moderación podrían resumir los diversos sentidos del concepto de discretio, y al respecto es notable el aporte de Ricardo de San Víctor, quien en sus Adnotationes mysticae in Psalmum 143 (P.L. 196, 381 D-382 A) distingue en ella cinco actividades: la dijudicatio, que decide lo que es lícito o no; la deliberatio, que distingue lo que conviene de lo que no conviene; la dispositio que discierne lo que está conforme al orden o no; la dispensatio, que diferencia lo oportuno de lo inoportuno, y la moderatio, que mantiene el término medio. Actividades todas que pertenecen a la inteligencia, cuya discretio interviene como un juicio de orden práctico en el ejercicio de todas las virtudes.

La discretio así comprendida corresponde a la virtud de prudencia, cuyo estudio sistemático a partir del siglo XIII -y ya desde los finales del siglo XII- abarcará todo lo que pertenecía a la discretio. Donde en Casiano, el adjetivo prudens acompaña discretio y en Beniamin minor (LXVIII) la prudencia aparece como un atributo de la discretio, pero es por los escolásticos, y en particular santo Tomás de Aquino, como el término prudentia llegará a reemplazar discretio, que conservará, sin embargo, dos significados: "discernimiento de los espíritus” y "moderación” (3).

\section{Casiano, Bernardo de Claraval y Ricardo de San Víctor}

En las obras de Ricardo, la discretio no se relaciona con el discernimiento de los espíritus entendido en sentido técnico, pero sí, y constantemente, significa discernimiento y medida.

El elogio de la medida y el rechazo de su contrario, la desmedida, pertenecen a la tradición griega-latina-cristiana. No es un tema del Antiguo Testamento, salvo en los textos influenciados directamente por la cultura griega, como el Libro de la Sabiduría.

Para los antiguos griegos, la medida es el elemento esencial de la belleza y de la virtud en todos los campos del actuar humano. Está ligada al equilibrio, a la sobriedad, al sentido de las proporciones y al orden. Es el mejor de los bienes (4).

(3) Cf. O. Lottin, Psychologie et morale aux XIIe et XIIIe siècles, t. 3, 2e p., 1949, Louvain, pp. 255-280.

(4) Esquilo, Agamenón, 378. 
Es una virtud que triunfa tanto en el cielo de los dioses como en el mundo de los sabios. Estaba expresada en una fórmula sucinta, atribuida a Solón y grabada en el frontis del templo de Apolo en Delfos: "Mêdén ágan". Para Platón y Aristóteles, es la virtud suprema, la que evita todo exceso, es el equilibrio entre los extremos. Está relacionada con la verdad, la justicia y todas las demás virtudes.

Para los monjes cristianos del Oriente, llámense Pacomio, Basilio o Gregorio de Nacianzo, el equilibrio y la discreción son virtudes fundamentales.

Entre los latinos, tanto el austero Jerónimo como Agustín aprecian sobremanera el $\mathrm{Ne}$ quid nimis de los griegos y de los latinos, pero es Juan Casiano quien ha sido el primero en exponer en forma más completa la doctrina de la discretio, madre de la medida, fuente y raíz de todas las virtudes, que ella inspira, rige y custodia. Es la "vía real" que recomendarán las Reglas de Benito y Columbano.

Continuador de Casiano, Bernardo de Claraval no ve en la discretio una virtud entre otras, sino la madre de las virtudes, sin la cual todo es vicio. La discretio equilibra el fervor y es, para el Doctor melifluo, la consumación de la perfección.

Es en esa línea tradicional donde Ricardo de San Víctor se inserta con profundas disertaciones sobre la discretio repartidas en varias de sus obras, especialmente en Beniamin minor. Nos recuerda que la discretio, discernimiento y medida, es una gracia y que no se limita a las virtudes morales. Se extiende al amor. El amor es una fuerza ciega, y a consecuencia del pecado, puede equivocarse en la elección de su objeto. Es la discretio que procura que sea amado lo que es realmente amable. Apoyada en el doble mandamiento que nos dejó el Señor, establece una jerarquía y fija la justa medida que corresponde a cada uno. Ella ordena nuestra caridad, que llegando a ser una caridad ordenada, ordinata caritas, pasa a ser al mismo tiempo un amor discernido y medido, discretus amor, el mismo que reina en la Santísima Trinidad (5).

La tradición posterior, en particular con Ignacio de Loyola y Francisco de Sales, recordará constantemente la necesidad de la discretio, pero en ningún autor el pensamiento acerca del discernimiento y de la medida ha tenido el nivel de desarrollo que ha tenido en Ricardo de San Víctor.

Su Beniamin minor, desarrollado con maestría y abundantes imágenes, ha dejado estampado para siempre la importancia de la discretio y el símbolo de esta virtud soberana: el hijo de Raquel-la razón, José, el más amado de los hijos de Jacob.

\section{RESUMEN.}

La estructura del alma y la antropología han sido temas abundantemente desarrollados por los autores cristianos medievales a partir de la expresión bíblica "imagen y semejanza".

En ese contexto conceptual, el Beniamin minor de Ricardo de San Víctor muestra cómo ratio y affectio necesitan la discretio para equilibrar todas las virtudes y poder acceder a la contemplación.

Ricardo, que ve en cada hijo de Jacob, un símbolo de las virtudes, atribuye la discretio a José, hijo de Raquel, quien a su vez representa la razón.

(5) Sobre esta materia ver F. Guimet, Caritas ordinata et amor discretus dans la théologie trinitaire de Richard de Saint-Victor. Revue du moyen âge latin, t.4, 1948, pp. 225-236. 
El artículo recuerda cómo, ya a partir del final del siglo XII, la discretio quedará absorta en la noción de prudencia. Ricardo siendo su último e importante exponente.

\begin{abstract}
The soul structure and the anthropology are topics that the christian authors of the Middle Age abundantly explained starting from the biblical expression imago et similitudo.

In that conceptual context, Beniamin minor of Richard of Saint Victor demonstrates that ratio and affectio need discretio in order to equilibrate all the virtues and to be able to accede to the contemplation.

Richard, who sees in every son of Jacob a symbol of the virtues, attributes discretio to Joseph, which is the son of Rachel, the symbol of reason.

The article shows that, from the end of the XIlth century, discretio will be absorbed in the virtue of prudentia. Richard is his last and more important exponent.
\end{abstract}

